\title{
Acidentes com animais peçonhentos no Brasil: revisão de literatura
}

\author{
Ana Thereza Arêa Leão de Oliveira ${ }^{i}$ \\ Angélica Florinda Pacheco Barbosa de Sousa ${ }^{\text {ii }}$ \\ Isadora de Castro Leite Alcantra ${ }^{\text {iii }}$ \\ Isadora Teixeira Nunes de Miranda ${ }^{\text {iv }}$ \\ Rosemarie Brandim Marques ${ }^{\mathfrak{}}$
}

\section{Registro DOI: http://dx.doi.org/10.22280/revintervol11ed3.389}

\begin{abstract}
Resumo
Dados fornecidos pelo Ministério da Saúde através do Sistema de Notificação de Agravos, ocorreram de 1975 à 20151.180 .844 acidentes humanos envolvendo serpentes e o mesmo valor para aranhas, 521.977 escorpião e 79.580 abelhas. O objetivo deste trabalho foi apresentar uma revisão bibliográfica sobre os principais tipos de acidentes com animais peçonhentos no Brasil, bem como os sinais e sintomas ocasionados. Realizou-se um levantamento bibliográfico através das bases de dados SciELO, Lilacs, PubMed e BVS, utilizando como principais palavras-chave: "animais peçonhentos", "acidentes com animais peçonhentos", "acidentes com serpentes", "acidentes com escorpiões", "acidentes com aranhas" e "acidentes com abelhas". Foram analisados 22 artigos em português e 1 em inglês. Concluíram-se que estes acidentes apresentam grande importância epidemiológica, pelo risco de causarem reações graves e até mesmo o óbito. Observou-se também que esses acidentes são subnotificados no Brasil, fazendose necessário um incentivo à pesquisa nessa área, para que haja um fornecimento maior de informações à população e profissionais de saúde quanto à frequência desses eventos.
\end{abstract}

Palavras-chave: Serpentes. Aranhas. Abelhas. Animais Peçonhentos.

\section{Accidents with venomous animals in Brazil: literature review}

\begin{abstract}
Data provided by the Ministry of Health through the System of Notification of Injuries, occurred from 1975 to 2015 1,180,844 human accidents involving snakes and the same value for spiders, 521,977 scorpions and 79,580 bees. The objective of this work was to present a bibliographical review on the main types of accidents with venomous animals in Brazil, as well as the signs and symptoms caused. A bibliographic survey was carried out through the SciELO, Lilacs, PubMed and VHL databases, using as main keywords: "venomous animals", "accidents with venomous animals", "accidents with snakes", "accidents with scorpions", "Accidents with spiders" and "accidents with bees". We analyzed 22 articles in Portuguese and 1 in English. It was concluded that these accidents have great epidemiological importance, because of the risk of causing serious reactions and even death. It was also observed that these accidents are underreported in Brazil, making it necessary to encourage research in this area, so that there is
\end{abstract}




\section{Revinter}

a greater supply of information to the population and health professionals regarding the frequency of these events.

Keywords: Serpents. Spiders. Bees. Venomous animals.

\section{Recebido em 10/05/2018 Aceito em 02/10/2018}

\section{INTRODUÇÃO}

Pelos dados fornecidos pelo Ministério da Saúde (MS) - Sistema de Notificação de Agravos (SINAN) ocorreram de 1975 à 2015 1.180.844 acidentes por serpentes e o mesmo valor para aranhas, 521.977 por escorpião e 79.580 por abelhas. Esses dados confirmam a importância epidemiológica dos acidentes com animais peçonhentos para a saúde pública do Brasil.

De acordo com o gênero de serpente, os acidentes são classificados em botrópico, crotálico, laquético e elapídico. Com as recentes mudanças taxonômicas das serpentes peçonhentas, os gêneros estão agora distribuídos de acordo com o tipo de acidente da seguinte forma: botrópico (Bothrops, Bothropoides, Bothriopsis, Bothrocophias e Rhinocerophis), crotálico (Crotalus), laquético (Lachesis) e elapídico (Micrurus e Leptomicrurus).Ocorrem por ano aproximadamente 20.000 casos de acidentes ofídicos no Brasil, sendo que é exatamente na Amazônia onde existe maior incidência de casos por habitantes (BERNARD; GOMES, 2012).

Entretanto, em virtude das maiores dificuldades de acesso aos serviços de saúde nessa região é de se esperar que haja subnotificação dos acidentes ofídicos. Apesar de a Amazônia apresentar maior incidência de acidentes ofídicos, a maioria dos estudos epidemiológicos sobre o ofidismo sempre foi desenvolvida na região sudeste do Brasil (BERNARD; GOMES, 2012).

Os raros estudos nacionais de acidentes ofídicos refletem a pouca importância que é dada a este tipo de agravo à saúde. Sugere-se a realização de análises utilizando-se dos dados secundários provenientes do SINAN, contribuindo para a qualificação desta fonte de informação e para que se possa traçar a real dimensão do problema nas diversas esferas de gestão do Sistema Único de Saúde (SUS) (COUTINHO et al., 2012) 


\section{Revinter}

Os acidentes escorpiônicos, por sua vez, são importantes em virtude da grande frequência com que ocorrem e da sua potencial gravidade, principalmente em crianças picadas pelo Tityus serrulatus. Dados do MS indicam a ocorrência de cerca de 8 mil acidentes/ano, com um coeficiente de incidência de aproximadamente três casos/100 mil habitantes. Os principais agentes de importância médica são: T. serrulatus, responsável por acidentes de maior gravidade, T. bahiensis e T. stigmurus (MINISTÉRIO DA SAÚDE, 2001).

Em relação às aranhas, segundo Barraviera e Ferreira Junior (2002), existem no mundo pelo menos 25 mil espécies potencialmente venenosas, cujos envenenamentos graves são provocados na maioria das vezes por aranhas fêmeas, pois os machos não são capazes de liberar quantidade de veneno suficiente para causar a morte. Apesar de relativamente negligenciados, quando comparados ao ofidismo, os acidentes causados por aranhas configuram-se como um problema de saúde pública, em especial, nas regiões tropicais do mundo (BRASIL et al., 2009).

As abelhas que pertencem à ordem Hymenoptera são os únicos insetos que possuem ferrões verdadeiros, entre eles, a família Apidae, grupo constituído de 10 mil espécies (MINISTÉRIO DA SAÚDE, 2001). As abelhas podem causar acidentes graves e morte, tanto por reação anafilática decorrente de uma única picada como por envenenamento decorrente de múltiplas picadas (PROGRAMA DE VIGILÂNCIA DE ACIDENTES COM ANIMAIS PEÇONHENTOS DO PARANÁ, 2013).

O objetivo deste trabalho foi apresentar uma revisão bibliográfica sobre os principais acidentes com animais peçonhentos no Brasil, os tipos de acidentes mais frequentes, bem como os sinais e sintomas ocasionados.

\section{METODOLOGIA}

Realizou-se um levantamento bibliográfico através de uma revisão de literatura nas bases de dados SciELO, Lilacs, PubMed e BVS, utilizando como principais palavras-chave: "animais peçonhentos", "acidentes com animais peçonhentos", “acidentes com serpentes", "acidentes com escorpiões", "acidentes com aranhas" e "acidentes com abelhas". Foram analisados 23 artigos, sendo 22 em português e 1 em inglês. 


\section{Revinter}

\section{RESULTADOS E DISCUSSÃO}

\subsection{Acidente Botrópico}

Pertencentes à família Viperidae, as jararacas compreendem um grupo de aproximadamente 30 espécies, e estão distribuídas por todo o território nacional, dentre esse grupo, as principais espécies são: Bothrops atrox, Bothrops erythromelas, Bothrops jararaca, Bothrops jararacussu, Bothrops moojeni e Bothrops alternatus. As serpentes jararaca são mais ativas no período da noite e durante os meses quentes. As fêmeas grávidas tendem a se manter em áreas onde conseguem se termorregular e se proteger. Além disso, tendem a serem maiores e mais volumosas que os machos. Para se aquecer as jararacas utilizam o calor da superfície do solo durante a noite (ALMEIDA et al., 2016).

De acordo com dados disponibilizados pelo MS/SVS - Sistema de Informação de Agravos de Notificação de 1975 a 2015 o acidente botrópico representou 15,2\% dos acidentes por serpentes e que $0,39 \%$ de seus casos vão à óbito pelo agravo notificado.

Sua peçonha possui importantes atividades fisiopatológicas, com lesões locais e destruição tecidual (ação proteolítica), ativa a cascata da coagulação podendo induzir incoagulabilidade sanguínea por consumo de fibrinogênio (ação coagulante), promove liberação de substâncias hipotensoras e provoca lesões na membrana basal dos capilares por ação das hemorraginas (ação hemorrágica), que associada à plaquetopenia e alterações da coagulação, promovem as manifestações hemorrágicas, frequentes neste tipo de acidente. No caso de serpente do gênero Bothrops, há uma diferença entre o veneno do filhote, que é predominantemente coagulante, e do adulto, com maior ação proteolítica e menor ação coagulante (PEREIRA; PINHO, 2001).

O quadro clínico desenvolvido pela vítima depende da quantidade de veneno inoculado, da localização da picada, da idade e, especialmente, do tempo decorrido entre o acidente e o atendimento médico, fato esse que pode acarretar na complicação do acidente (ALMEIDA et al., 2016).

O quadro clínico caracteriza-se por manifestações locais importantes, como dor e edema. Frequentemente, surgem equimoses, lesões bolhosas e sangramentos no local da picada. Nos casos mais graves, pode ocorrer necrose de tecidos moles com formação de abscessos e desenvolvimento de Síndrome Compartimental, podendo ter como sequelas a perda Revinter, v. 11, n. 03, p. 119-136, out. 2018.

Página 122 | 136 


\section{Revinter}

funcional ou mesmo anatômica do membro acometido. As manifestações sistêmicas incluem sangramentos em ferimentos cutâneos preexistentes e hemorragias à distância, como gengivorragias, epistaxes, hematêmese e hematúria (PEREIRA; PINHO, 2001).

Além disso, podem ocorrer náuseas, vômitos, sudorese, hipotensão arterial e, mais raramente, choque. As complicações sistêmicas mais comuns são o choque, a insuficiência renal aguda, a septicemia e a coagulação intravascular disseminada, tendo patogênese multifatorial e sendo causas frequentes de óbitos (PEREIRA; PINHO, 2001).

O prognóstico no acidente botrópico é bom, com mortalidade abaixo de $1 \%$ dos casos tratados. Há possibilidade de sequelas anatômicas locais e funcionais, devido à necrose de tecidos e infecção secundária. A insuficiência renal que pode ocorrer é reversível na maioria dos casos (CAMPOS et al., 1999).

O tratamento específico consiste na administração o mais precocemente possível, por via endovenosa do soro antibotrópico $(\mathrm{SAB})$ e, na falta deste, das associações antibotrópicocrotálico (SABC) ou antibotrópico-laquético (SABL), em ambiente hospitalar. As medidas gerais incluem procedimentos indicados para tratamento das alterações locais. O local de inoculação do veneno deve ser limpo com água e sabão. A elevação do membro acometido pouco acima do resto do corpo pode facilitar a diminuição do edema. Os tecidos necrosados devem ser cuidadosamente debridados e os abscessos drenados. A fasciotomia deve ser realizada se ocorrer Síndrome Compartimental. Adequada hidratação, profilaxia contra o tétano e uso de analgésicos são medidas complementares importantes. A antibioticoterapia é reservada para casos onde sejam verificados sinais clínicos e laboratoriais de infecção. Considerar a necessidade de cirurgia reparadora nas perdas extensas de tecidos, e preservar o segmento acometido até que se tenha certeza de que nada poderá ser feito para recuperá-lo ou se está em risco à vida do paciente (PEREIRA; PINHO, 2001).

\subsection{Acidente Crotálico}

Na explicação do Manual do MS (1998), as serpentes do gênero Crotalus estão representadas no país por apenas uma espécie, a Crotalus durissus e são encontradas em campos abertos, áreas secas, arenosas e pedregosas, raramente na faixa litorânea. Não possuem hábito 
de atacar e, quando ameaçadas, denunciam sua presença pelo ruído característico do guizo ou chocalho, presente na cauda.

De acordo com dados disponibilizados pelo MS/SVS de 1975 a 2015 o acidente crotálico representou 1,56\% dos acidentes por serpentes e que 1,00\% de seus casos vão à óbito pelo agravo notificado.

Segundo Saraiva (2012) o acidente crotálico é o segundo acidente mais prevalente dentre os ofídios peçonhentos. Além disso, o veneno crotálico praticamente não produz lesão local, possuindo principalmente três atividades com importância clínica conhecida: atividade neurotóxica, com ação periférica, causando paralisia flácida da musculatura esquelética, principalmente ocular, facial e às vezes, da respiração, com consequência insuficiência respiratória; atividade coagulante, provocando a ocorrência de sangramento e distúrbios da coagulação por consumo de fibrinogênio; e atividade miotóxica sistêmica, causando rabdomiólise generalizada, podendo evoluir para insuficiência renal aguda.

Para Ribeiro (1995), o quadro clínico local geralmente ocorre manifestações discretas como dor, parestesia local ou regional, que pode persistir por tempo variável, podendo ser acompanhada de edema ou eritema no ponto da picada.

Em relação a miotoxicidade do veneno, é evidenciada por intensa mialgia generalizada, que pode ser acompanhada por discreto edema muscular e a miólise causa mioglobinúria que confere cor avermelhada ou vinhosa à urina. Os pacientes devem ser bem hidratados para prevenir a insuficiência renal. O tratamento específico é a infusão do soro anticrotálico (SAC) ou soro antibotrópico-crotálico (SABC) endovenoso (MINISTÉRIO DA SAÚDE, 2001). Os acidentes crotálicos são classificados em casos leves, moderados e graves de acordo com as manifestações clínicas.

Segundo Saraiva et al. (2012), a principal complicação desse tipo de acidente é a insuficiência renal aguda, com necrose tubular, geralmente de instalação nas primeiras 48 horas. De acordo com Pinho et al. (2000), a insuficiência renal é mais comum nos envenenamentos crotálicos, entre 9 e $31 \%$ dos casos. Na sua gênese estão envolvidos diversos mecanismos como rabdomiólise, coagulação intravascular e ação direta de nefrotoxinas.Além disso, outros fatores relacionados com o risco de desenvolvimento de insuficiência renal aguda são a idade (mais 


\section{Revinter}

frequente nas crianças), tamanho da serpente, local da picada, grau de hidratação do paciente, tempo entre a picada e administração do soro específico.

A síndrome do desconforto respiratório do adulto (SDRA) e a insuficiência de múltiplos órgãos e sistemas (IMOS) são descritas como complicações raras de um acidente crotálico. (BARRAVIERA et al., 2005)

\subsection{Acidente Laquético}

De acordo com Rosenthal et. al (2002), o gênero Lachesis só existe as espécies Lachesis mutamuta e Lachesis mutarhombeata. Estas são encontradas em áreas florestais como Amazônia, Mata Atlântica e algumas enclaves de matas úmidas do Nordeste.

Poucos relatos existem na literatura e por se tratar de serpentes encontradas em áreas florestais, onde a densidade populacional é baixa e o sistema de notificação não é eficiente, as informações disponíveis sobre esses acidentes são escassas (FUIJOKA, 2015).

Segundo Pardal et al. (2007), o veneno laquético possui ações proteolíticas, coagulantes, hemorrágicas e neurotóxica, que dependendo da quantidade de veneno introduzido vão ser responsáveis pela gravidade e manifestações clínicas. Os sintomas sinais se caracterizam por dor, edema, bolhas, necrose, distúrbios da coagulação, manifestações hemorrágicas diversas e uma síndrome vagal, que se manifesta por vômitos, dores abdominais, diarréia e bradicardia. $\mathrm{O}$ tratamento para o envenenamento laquético é baseado na gravidade do acidente (moderado ou grave). No Brasil, está disponível para o tratamento o soro antibotrópico-laquético (SABL), de administração via intravenosa.

Segundo com Borges (1999), o quadro clínico é semelhante às descritas no acidente botrópico, predominando a dor e edema, que podem progredir para todo o membro. Podem surgir vesículas e bolhas de conteúdo seroso ou sero-hemorrágico nas primeiras horas após o acidente. Nas manifestações sistêmicas são relatados hipotensão arterial, vertigens, escurecimento da visão, bradicardia, cólicas abdominais e diarréia ("síndrome vagal”). No geral, podemos observar que os acidentes botrópico e laquético são muito semelhantes do ponto de vista clínico, sendo, na maior parte dos casos, é difícil o diagnóstico diferencial. As manifestações da "síndrome vagal” poderiam auxiliar na distinção desses acidentes. 
No levantamento epidemiológico de Fuijoka (2015) sobre os acidentes ofídicos no município de Umuarama e região, verificou-se que o gênero Bothrops foi o responsável pela maioria dos casos de acidentes ofídicos com serpentes peçonhentas com 5,2\% dos casos, seguido do gênero Crotalus com 3,9\% e outros 90,9\% tiveram seu gênero ignorado, pois no momento do acidente, as vítimas não conseguiram identificar ou capturar o animal agressor. $\mathrm{O}$ elevado índice de dados ignorados no gênero pode estar relacionado também o fato de talvez decorra da acomodação dos responsáveis em preencher a ficha de notificação corretamente, desconsiderando a importância ecológica e epidemiológica que os referidos dados podem trazer quando feito este tipo de levantamento descrito, dando-nos pouco da real dimensão que este dado pode representar.

\subsection{Acidente Elapídico}

As serpentes do gênero Micrurus compreendem 18 espécies distribuídas em todo o território brasileiro. As espécies mais comuns são a $M$. corallinus, encontrada na região sul e litoral da região sudeste; $M$. frontalis, também encontrada nas regiões sul, sudeste e parte do centro-oeste e $M$. lemniscatus, distribuídas nas regiões norte e centro-oeste (PEREIRA; PINHO, 2001). Segundo o SINAN, corresponde a $0,16 \%$ dos acidentes por serpentes registrados no Brasil.

O veneno elapídico possui constituintes tóxicos denominados de neurotoxinas, substâncias de baixo peso molecular que são rapidamente absorvidas e difundidas para os tecidos, explicando a precocidade dos sintomas de envenenamento. Este veneno produz bloqueio neuromuscular (pós-sináptico) levando à paralisia muscular, competindo com a acetilcolina (Ach) pelos receptores colinérgicos, atuando de modo semelhante ao curare (PEREIRA; PINHO, 2001).

O quadro clínico caracteriza-se por sintomas que surgem precocemente, em menos de uma hora após a picada. Há discreta dor local, geralmente acompanhada de parestesia com tendência a progressão proximal. As manifestações sistêmicas incluem vômitos, fraqueza muscular progressiva, ptose palpebral, oftalmoplegia e a presença de fácies miastênica ou "neurotóxica". Também podem surgir mialgia localizada ou generalizada, dificuldade para se manter na posição ereta, dificuldade para deglutir, devido à paralisia do véu palatino. A paralisia flácida da musculatura respiratória compromete a ventilação, podendo evoluir para 
insuficiência respiratória aguda e apnéia, semelhante ao que ocorre no acidente crotálico. $\mathrm{O}$ acidente elapídico é considerado muito grave, podendo causar a morte da vítima em curto intervalo de tempo (PEREIRA; PINHO, 2001).

O tratamento específico é a administração, por via endovenosa do soro antielapídico (SAE). O soro antielapídico (SAE) deve ser administrado na dose de 10 ampolas, pela via intravenosa. Nos casos com manifestações clínicas de insuficiência respiratória, é fundamental manter o paciente adequadamente ventilado, seja por máscara e AMBU, intubação traqueal e AMBU ou até mesmo por ventilação mecânica. Estudos clínicos controlados e comunicações de casos isolados atestam a eficácia do uso de anticolinesterásicos (neostigmina) em acidentes elapídicos humanos. A principal vantagem desse procedimento, desde que realizado corretamente, é permitir uma rápida reversão da sintomatogia respiratória enquanto o paciente é transferido para centros médicos que disponham de recursos de assistência ventilatória mecânica (MINISTÉRIO DA SAÚDE, 2001).

\subsection{Escorpionismo}

Os acidentes escorpiônicos são importantes em virtude da grande frequência com que ocorrem e da sua potencial gravidade, principalmente em crianças picadas pelo Tityus serrulatus. Dados do MS indicam a ocorrência de cerca de 8 mil acidentes/ano, com um coeficiente de incidência de aproximadamente três casos/100 mil habitantes. Os principais agentes de importância médica são: T. serrulatus, responsável por acidentes de maior gravidade, T. bahiensis e T. stigmurus (MINISTÉRIO DA SAÚDE, 2001).

As picadas atingem predominantemente os membros superiores, 65\% das quais acometendo mão e antebraço. A maioria dos casos tem curso benigno. Os óbitos têm sido associados, com maior frequência, a acidentes causados por T. serrulatus, ocorrendo mais comumente em crianças menores de 14 anos (MINISTÉRIO DA SAÚDE, 2001).

A toxina escorpiônica atua em sítios específicos dos canais de sódio, produzindo despolarização das terminações nervosas pós-ganglionares dos sistemas simpático, parassimpático e da medula da supra-renal, desencadeando liberação de adrenalina, noradrenalina e acetilcolina. Esses neurotransmissores são responsáveis pela maior parte dos sintomas e sinais clínicos, observados nos pacientes, sendo muito variados e mutáveis. O quadro 
clínico estabelecido vai depender da predominância dos efeitos ora colinérgicos ora adrenérgicos (CUPO et. al., 2003).

- Acidentes leves: somente presente a sintomatologia local, sendo a dor referida em praticamente $100 \%$ dos casos. Podem ocorrer vômitos ocasionais, taquicardia e agitação discretas, decorrentes da ansiedade e do próprio fenômeno doloroso (CUPO et. al., 2003).

- Acidentes moderados: além dos sintomas locais, presentes também algumas manifestações sistêmicas, isoladas, não muito intensas, como sudorese, náuseas, vômitos, hipertensão arterial, taquicardia, taquipnéia e agitação (CUPO et. al., 2003).

-Acidentes graves: as manifestações sistêmicas são bastante evidentes e intensas. Vômitos profusos e frequentes (a intensidade e a frequência dos vômitos são um sinal premonitório e sensível da gravidade do envenenamento), sudorese generalizada e abundante, sensação de frio, pele arrepiada, palidez, agitação psicomotora acentuada, podendo estar alternada com sonolência, hipotermia, taqui ou bradicardica, extra-sistolias, hipertensão arterial, taqui e hiperpnéia, tremores e espasmos musculares (CUPO et. al., 2003).

Pode haver evolução para choque cardiocirculatório e edema agudo do pulmão, sendo as causas mais frequentes de óbito no escorpionismo (CUPO et. al., 2003).

O tratamento visa neutralizar o mais rápido possível a toxina circulante, combater os sintomas do envenenamento e dar suporte às condições vitais do paciente. Todas as vítimas de picada de escorpião, mesmo que o quadro seja considerado leve, devem ficar em observação hospitalar nas primeiras 4 a $6 \mathrm{~h}$ após o acidente, principalmente as crianças. Nos casos moderados, recomenda-se, pelo menos, 24 a 48 h de observação e, nos casos graves, com instabilidade dos sistemas cardiorrespiratórios, está indicada a internação com monitorização contínua dos sinais vitais (CUPO et. al., 2003).

O soro antiescorpiônico (ou antiaracnídico) está formalmente indicado em todos os casos graves. Nos moderados, tem sido nossa conduta utilizá-lo apenas em crianças abaixo de sete anos, por constituírem grupo de risco. Para os demais, preconizamos, inicialmente, combater a dor e manter o paciente sob observação e, a qualquer sinal de agravamento do quadro, iniciar a soroterapia. É importante ressaltar que a gravidade do quadro já se manifesta dentro da primeira ou da segunda hora após acidente (CUPO et. al., 2003). 
O prognóstico geralmente é bom, principalmente nos casos leves e moderados. Nos casos graves, as primeiras $24 \mathrm{~h}$ são críticas, período no qual podem surgir as temidas complicações cardiocirculatórias e pulmonares, que podem levar o paciente à morte (CUPO et. al., 2003).

\subsection{Araneísmo}

Segundo Barraviera e Ferreira Junior (2002), existem no mundo pelo menos 25 mil espécies de aranhas potencialmente venenosas, cujos envenenamentos graves são provocados na maioria das vezes por aranhas fêmeas, pois os machos não são capazes de liberar quantidade de veneno suficiente para causar a morte. Apesar de relativamente negligenciados, quando comparados ao ofidismo, os acidentes causados por aranhas configuram-se como um problema de saúde pública, em especial, nas regiões tropicais do mundo (BRASIL et al., 2009).

Segundo os dados epidemiológicos do MS, entre os anos de 2000 e 2016 houveram 359.985 casos de acidentes por aranhas, sendo o ano de 2015 com maior número, de 30.373 casos e a região Sul do Brasil, com 242.463 casos. No mesmo período, o número de óbitos registrados foi de 174, com destaque para o ano de 2016, com 25 óbitos e para a região Nordeste, com 11 óbitos no total.

O coeficiente de incidência dos acidentes araneídicos situa-se em torno de 1,5 casos por 100 mil habitantes, sendo a maioria das notificações provem das regiões Sul e Sudeste. No Brasil, existem três gêneros de aranhas de importância médica: Phoneutria, Loxosceles e Latrodectus (MINISTÉRIO DA SAÚDE, 2001).

É importante ressaltar que, sob a análise de um período mais longo (1975-2015), de acordo com o SINAN, o maior número de acidentes se deve ao gêmero Loxosceles, enquanto a maior porcentagem de óbitos, em relação à quantidade de acidentes causados, deve-se ao gênero Latrodectus $(0,1 \%)$.

As aranhas do gênero Phoneutria são conhecidas popularmente como aranhas armadeiras, sendo animais errantes que caçam principalmente à noite. São encontradas principalmente na região Amazônica, Goiás, Mato Grosso do Sul, Minas Gerais, Paraná, Rio 
de Janeiro, Rio Grande do Sul, São Paulo, Santa Catarina, Espírito Santo e Paraná (MINISTÉRIO DA SAÚDE, 2001).

Os acidentes ocorrem frequentemente dentro das residências e nas suas proximidades, ao se manusearem material de construção, entulhos, lenha ou calçando sapato (MINISTÉRIO DA SAÚDE, 2001). Podem ocorrer alterações clínicas como são dor, eritema, edema, parestesia, sudorese, taquicardia, agitação, hipertensão, vômitos, sialorreia, priapismo, hipotensão arterial, choque e edema agudo de pulmão (LISE; COUTINHO; GARCIA, 2006).

O tratamento é sintomático ou específico com a soroterapia, que tem sido formalmente indicada nos casos com manifestações sistêmicas em crianças e em todos os acidentes graves. O prognóstico é bom, os óbitos são muito raros. Lactentes e pré-escolares, bem como os idosos, devem sempre ser mantidos em observação pelo menos por seis horas (MINISTÉRIO DA SAÚDE, 2001).

Já as aranhas do gênero Loxosceles são conhecidas popularmente como aranhasmarrons, não agressivas, picando apenas quando comprimidas contra o corpo. Provocam acidentes principalmente no interior de domicílios, ao se refugiar em vestimentas. Predominam principalmente nos estados do Sul do país e no estado de São Paulo (MINISTÉRIO DA SAÚDE, 2001). São caracterizados como os mais graves dessa região, pois o seu veneno tem ação lítica sobre a membrana celular das hemácias e do endotélio vascular, provocando intensa reação inflamatória, eritema, edema, cefaléia e febre alta (LISE; COUTINHO; GARCIA, 2006).

A lesão cutânea pode evoluir para necrose seca, em cerca de 7 a 12 dias, que, ao se destacar em 3 a 4 semanas, deixa uma úlcera de difícil cicatrização. Nos casos mais graves, manifestações clínicas em virtude de hemólise intravascular como anemia, icterícia e hemoglobinúria que se instalam geralmente nas primeiras 24 horas. Este quadro pode ser acompanhado de petéquias e equimoses, relacionadas à coagulação intravascular disseminada (CIVD), com principal complicação a insuficiência renal aguda. A indicação de soroterapia é presente nos casos de gravidade moderada e grave (MINISTÉRIO DA SAÚDE, 2001).

O gênero Latrodectus, por sua vez, são conhecidas popularmente como viúvas-negras e são distribuídas principalmente na região Nordeste do país. O veneno desse gênero atua sobre as terminações sensitivas e sobre o sistema nervoso autônomo pela liberação de Revinter, v. 11, n. 03, p. 119-136, out. 2018. 


\section{Revinter}

neurotransmissores. As manifestações locais se apresentam como dor, pápula, eritema, sudorese localizada e hiperestesia com infarto ganglionar regional. As manifestações sistêmicas são tremores, ansiedade, excitação, cefaléia, insônia, prurido, alterações do comportamento, choque, retenção urinária e sensação de morte (OLIVEIRA et al., 1999 apud LISE; COUTINHO; GARCIA, 2006).

O tratamento é sintomático e o soro antilatrodectus (SALatr) é indicado nos casos graves, na dose de uma a duas ampolas por via intramuscular. A melhora do paciente ocorre de 30 minutos a três horas após a soroterapia (MINISTÉRIO DA SAÚDE, 2001).

O controle e a prevenção podem determinar a diminuição dos índices de araneísmo e, consequentemente, a morbidade e a mortalidade (CASTRO; SILVA; SILVA, 2009). O desconhecimento das pessoas a respeito do manejo e da biologia das aranhas possibilita o seu aparecimento e manutenção em locais que poderiam ser evitados, especialmente naqueles em que as pessoas permanecem por longos períodos, como na residência, escola e nos locais de trabalho (CHENET et al., 2009).

\subsection{Acidentes por abelhas}

Pertencem à ordem Hymenoptera os únicos insetos que possuem ferrões verdadeiros, entre eles as abelhas, pertencentes a família Apidae, grupo constituído de 10 mil espécies (MINISTÉRIO DA SAÚDE, 2001). Esses animais podem causar acidentes graves e morte, tanto por reação anafilática decorrente de uma única picada como por envenenamento decorrente de múltiplas picadas. (PROGRAMA DE VIGILÂNCIA DE ACIDENTES COM ANIMAIS PEÇONHENTOS DO PARANÁ, 2013)

A incidência dos acidentes por himenópteros ainda não é totalmente certa, porém a hipersensibilidade provocada por picada de insetos, de grande importância, tem sido estimada, em $0,4 \%$ a $10 \%$ nas populações estudadas. As reações alérgicas tendem a ocorrer preferencialmente em adultos e nos indivíduos profissionalmente expostos (MINISTÉRIO DA SAÚDE, 2001).

As reações desencadeadas pela picada de abelhas são variáveis de acordo com o local e o número de ferroadas, as características e o passado alérgico do indivíduo atingido, variando 


\section{Revinter}

desde manifestações locais a manifestações sistêmicas. Habitualmente, após uma ferroada, há dor aguda local, associada à vermelhidão, prurido e edema por várias horas, alterações que podem ser seguidas de enduração ou não. Em certos indivíduos podem ocorrer manifestações sistêmicas, com características de anafilaxia clássica logo após o acontecimento, também podendo estar presentes cefaléia, vertigens e calafrios, agitação psicomotora, sensação de opressão torácica e outros sintomas e sinais, com destaque para hipotensão (MINISTÉRIO DA SAÚDE, 2001).

Já nos acidentes provocados por ataque múltiplo de abelhas desenvolve-se um quadro tóxico generalizado denominado síndrome de envenenamento, no qual há dados indicativos de hemólise intravascular e rabdomiólise. Alterações neurológicas como torpor e coma, hipotensão arterial, oligúria/anúria e insuficiência renal aguda podem ocorrer. (MINISTÉRIO DA SAÚDE, 2001).

A primeira medida a ser tomada trata-se da retirada dos ferrões, que deve ser rápida e cuidadosa, independente da técnica utilizada (PROGRAMA DE VIGILÂNCIA DE ACIDENTES COM ANIMAIS PEÇONHENTOS DO PARANÁ, 2013). Recomenda-se a retirada por raspagem no caso de múltiplas ferroadas, pois a compressão poderá espremer a glândula ligada ao ferrão e inocular no paciente o veneno ainda existente (MINISTÉRIO DA SAÚDE, 2001).

As reações tóxicas locais podem ser tratadas com compressas geladas e analgésicos e podem ser usados corticóides, anti-histamínicos e antiinflamatórios não esteroidais, de forma sistêmica, para alívio de sintomas. Deve-se ressaltar a atenção para os pacientes com picadas em boca ou pescoço pela possibilidade de obstrução das vias aéreas. Em casos graves, tem-se considerado o uso empírico de altas doses de anti-histamínicos e corticosteróides, além da administração de adrenalina, assim como a exsanguíneo-transfusão e plasmaferese, como forma de prevenção das complicações da síndrome do envenenamento. As reações alérgicas sistêmicas devem ser manejadas de acordo com o grau de gravidade, utilizando medidas de suporte avançado de vida (PROGRAMA DE VIGILÂNCIA DE ACIDENTES COM ANIMAIS PEÇONHENTOS DO PARANÁ, 2013).

Segundo o Ministério da Saúde, entre os anos 2000 e 2016 houveram 121.676 casos de acidentes por abelhas no Brasil, sendo o ano de 2014 o que teve maior incidência, com o valor 


\section{Revinter}

absoluto de 14.062 casos. Em relação a óbitos, no mesmo período, foram registrados 358, com o ano de 2013 apresentando o maior número, de 37 mortes devidas a picadas de abelhas. Em ambas as análises, a região sudeste do país foi a que obteve os maiores valores.

Segundo a Vigilância de Saúde do Paraná, os principais constituintes dos venenos de abelhas são: fosfolipase, hialuronidase, fosfatase ácida, apamina, aminas biogênicas, peptídeo degranulador de mastócitos e melitina, com destaque para os dois últimos, com forte papel no quadro de intoxicação histamínica resultante do acidente e na destruição de membranas celulares, mitocôndrias, hemácias, células musculares, hepatócitos, fibroblastos, mastócitos e leucócitos. Além disso, nos venenos dos himenópteros são encontrados componentes alérgenos que são capazes de desencadear respostas imunológicas em humanos, com destaque para a fosfolipase A no caso das abelhas.

As abelhas de importância no Brasil são as produtoras de mel, Apis mellifera, mansas, porém poucos produtivas e as abelhas africanizadas, híbridos que surgiram pelo cruzamento de colônias de uma subespécie da África com as abelhas européias e o resultado foi o aparecimento de uma abelha mais produtiva, porém com as características agressivas das abelhas africanas (PROGRAMA DE VIGILÂNCIA DE ACIDENTES COM ANIMAIS PEÇONHENTOS DO PARANÁ, 2013).

\section{CONCLUSÃO}

Os acidentes por animais peçonhentos apresentam grande importância visto que podem causar reações graves e levar o indivíduo ao óbito, mesmo com sua incidência moderada, porém não insignificante. Além disso, de modo geral, esses acidentes são subnotificados no Brasil. Portanto, faz-se necessário um incentivo à pesquisa nessa área, com objetivo de fornecer maiores informações à população e profissionais da área de saúde quanto à frequência desses eventos, para permitir uma identificação mais fácil da espécie envolvida e da conduta adequada em cada caso e ainda podendo evitar acidentes preveníveis com esses animais, diminuindo a morbidade e a mortalidade.

\section{REFERÊNCIAS BIBLIOGRÁFICAS}

Revinter, v. 11, n. 03, p. 119-136, out. 2018.

Página 133 | 136 


\section{Revinter}

ALMEIDA, M. M; et al. Revisão sistemática: as principais complicações do acidente botrópico. Portal de revistas eletrônicas PUC Goiás, 2016.

BARRAVIERA, B.; FERREIRA, J. Acidentes ofídicos. In: Veronesi R. Veronesi: tratado de infectologia. 3a ed. rev. e atual. São Paulo: Atheneu; 2005. p.1929-47.

BERNARDE, P. S.; GOMES, J. O. Serpentes peçonhentas e ofidismo em Cruzeiro do Sul, Alto Juruá, Estado do Acre, Brasil. Acta Amazônica, 2012.

BOCHNER, R.; STRUCHINER, C. J. Epidemiologia dos acidentes ofídicos nos últimos 100 anos no Brasil: uma revisão. Cad. Saúde Pública. Rio de Janeiro, 2003.

BORGES, T. Serpentes Peçonhentas. São Paulo: Atheneu, 1999.

BRAZIL, T. K.; et al. Aranhas de importância médica do Estado da Bahia, Brasil. Gazeta Médica da Bahia, v. 79, n. 1, p. 32-37, 2009.

CAMPOS, J. A.; et al. Acidentes por animais peçonhentos na infância. Jornal de Pediatria. Rio de janeiro, 1999.

CASTRO, A. P.; SILVA, T. C.; SILVA, J. C. R. Ocorrência, controle e prevenção de aranhas e escorpiões no nordeste brasileiro. 2009.

CHENET, D. C.; et al. Incidência de Aranhas de Importância em Saúde Pública em Curitibanos, Santa Catarina. Revista Ciência \& Saúde, Porto Alegre, v. 2, n. 1, p. 25-29, jan./jun. 2009.

COUTINHO, L. A.; et al. Perfil epidemiológico dos acidentes ofídicos no Estado da Paraíba. Epidemol. Serv saúde. Brasília, 2012.

CUPO, P; AZEVEDO-MARQUES, M. M; HERING, S. E. Acidentes por animais peçonhentos: Escorpiões e aranhas. Simpósio: URGÊNCIAS E EMERGÊNCIAS DERMATOLÓGICAS E TOXICOLÓGICAS, Ribeirão Preto, v. 36, p. 490-497, 2003. 


\section{Revinter}

FUJIOKA, D. K. T. ASPECTOS EPIDEMIOLÓGICOS DOS ACIDENTES OFÍDICOS NOTIFICADOS NO MUNICÍPIO DE UMUARAMA E REGIÃO- PARANÁ. 2015. Trabalho de conclusão de curso (Especialização) - Universidade Tecnológica Federal do Paraná. Medianeira, 2015.

LISE, F.; COUTINHO, S. E. D.; GARCIA, F. R. M. Características Clínicas do Araneísmo em Crianças e Adolescentes no Município de Chapecó, Estado de Santa Catarina, Brasil. Acta Sci Health Sci, Maringá, v. 28, n. 1, p. 13-16, 2006.

MAGALHÃES, R. A. Rabdomiólise Secundária a acidente ofídico crotálico. Rev. Inst. Méd. Trop. São Paulo, 1986.

MINISTÉRIO DA SAÚDE. Manual de diagnóstico e tratamento de acidentes por animais peçonhentos. Brasília: Fundação Nacional de Saúde, 2001.

PEREIRA, I. D.; PINHO, F. M. O. Ofidismo. Rev. Assoc. Med Bras. São Paulo, 2001.

PINHO, F. O.; VIDAL, E. C.; BURDMANN, E. A. Atualização em insuficiência renal aguda: insuficiência renal aguda após acidente crotálico. J BrasNefrol. 2000; 22(3):162-8.

PROGRAMA DE VIGILÂNCIA DE ACIDENTES COM ANIMAIS PEÇONHENTOS DO PARANÁ. Superintendência de Vigilância em Saúde. Acidentes com himenópteros abelhas, vespas e formigas. Paraná, 2013.

RAVIERA, B.; FERREIRA JUNIOR, R. S. Artrópodes: de importância médica. Rio de Janeiro: EPUB, 2002.

RIBEIRO, L. A. Epidemiologia dos Acidentes por Serpentes Peçonhentas: estudo de casos atendidos em 1988. Rev. Saúde Pública, 1995.

ROSENTHAL, R.; et al. Intestinal ischemia after bushmaster (Lachesismuta) snakebite - a case report. Toxicon. 2002, 40(2): 217-220.

SARAIVA, M. G.; et al. Perfil epidemiológico dos acidentes ofídicos no Estado da Paraíba, Brasil, 2005 a 2010. Epidemiol. Serv. Saúde, Brasília, 21(3):449-456, jul-set 2012. 


\section{Revinter}

SILVA, J. C.; et al. Perfil clínico epidemiológico dos acidentes ofídicos ocorridos na ilha de Colares, Pará, Amazônia Oriental. Semina: Ciências Biológicas e da Saúde. Londrina, 2015.

\footnotetext{
' Graduanda em Medicina pela Faculdade de Ciências Médicas da Universidade Estadual do Piauí.

ii Graduanda em Medicina pela Faculdade de Ciências Médicas da Universidade Estadual do Piauí.

iii Graduanda em Medicina pela Faculdade de Ciências Médicas da Universidade Estadual do Piauí.

iv Graduanda em Medicina pela Faculdade de Ciências Médicas da Universidade Estadual do Piauí.

${ }^{\vee}$ Graduação em Farmácia pela Universidade Federal do Piauí; Tecnóloga em Processamento de dados pela Universidade Estadual do Piauí; Mestrado em Ciências Farmacêuticas pela Universidade Federal do Ceará; Doutorado pela RENORBIO. E-mail para contato: rosebmarques@hotmail.com
} 